Portland State University

PDXScholar

\title{
Variation in Sex Allocation and Floral Morphology in an Expanding Distylous Plant Hybrid Complex
}

Jennifer Rhode Ward

University of North Carolina at Asheville

M. Leigh Cowart

University of North Carolina at Asheville

Julie Clifford

University of North Carolina at Asheville

Mieko Camp

Tennessee Technological University

Mitchell B. Cruzan

Portland State University, cruzan@pdx.edu

Follow this and additional works at: https://pdxscholar.library.pdx.edu/bio_fac

Part of the Plant Sciences Commons

Let us know how access to this document benefits you.

\section{Citation Details}

Ward, J. R., Cowart, M. L., Clifford, J., Camp, M., \& Cruzan, M. B. (2014). Variation in Sex Allocation and Floral Morphology in an Expanding Distylous Plant Hybrid Complex. International Journal of Plant Sciences, 175(5), 518-525.

This Article is brought to you for free and open access. It has been accepted for inclusion in Biology Faculty Publications and Presentations by an authorized administrator of PDXScholar. Please contact us if we can make this document more accessible: pdxscholar@pdx.edu. 
Int. J. Plant Sci. 175(5):518-525. 2014.

(C) 2014 by The University of Chicago. All rights reserved.

1058-5893/2014/17505-0002\$15.00 DOI: $10.1086 / 675695$

\title{
VARIATION IN SEX ALLOCATION AND FLORAL MORPHOLOGY IN AN EXPANDING DISTYLOUS PLANT HYBRID COMPLEX
}

\author{
Jennifer Rhode Ward, ${ }^{1, *}$ M. Leigh Cowart,* Julie Clifford,* Mieko Camp, + and Mitchell B. Cruzan‡ \\ *Biology Department, University of North Carolina at Asheville, Asheville, North Carolina 28804, USA; +Department of Biology, \\ Tennessee Technological University, Cookeville, Tennessee 38505, USA; and ¥Department of Biology, \\ Portland State University, Portland, Oregon 97201, USA
}

Editor: Susan J. Mazer

Premise of research. Sex allocation, the relative energy devoted to producing pollen, ovules, and floral displays, can significantly affect reproductive output and population dynamics. In this study, we investigated floral morphology and gamete production in bisexual, distylous plants from a self-incompatible hybrid complex (Piriqueta cistoides ssp. caroliniana Walter [Arbo]; Turneraceae). Sampling focused on two parent types (C, $\mathrm{V})$ and their stable hybrid derivative $(\mathrm{H})$. Since $\mathrm{H}$ morphotypes are heterotic for growth and fruit production, we hypothesized that they would produce larger flowers with more gametes. We also anticipated that plants with long styles (long morphs) would produce less pollen than short morphs, since long-morph pollen is larger.

Methodology. Over two consecutive summers, flowers were collected from 1465 individual plants in 28 field populations. Floral parameters were measured digitally, and each flower's pollen number, ovule number, and stigma-anther separation was quantified under a dissecting microscope. Gamete production $(n=332)$ and stigma-anther separation $(n=119)$ were also quantified for plants from a greenhouse accession.

Pivotal results. Floral display differed among morphotypes, with $\mathrm{H}$ plants producing the largest flowers and $\mathrm{C}$ plants displaying the least petal separation. Hybrid morphotypes produced significantly more pollen than parental morphotypes, and pollen quantity was significantly greater for long morphs. Ovule production, however, was greatest for V flowers. Stigma-anther separation differed between years and style morphs (greater for short morphs) but not among morphotypes or within a single season.

Conclusions. Differences in pollen production between morphs were not consistent with trade-offs in pollen size and number or selection for increased male function in short morphs. Greater stigma-anther separation in short morphs supported the hypothesis of selection to reduce pollen interference. Enhanced floral display and pollen production followed other heterotic traits observed in H morphotypes. The superior ability of $\mathrm{H}$ morphotypes to attract pollinators and sire seeds might partially explain this hybrid zone's continuing expansion.

Keywords: distyly, floral morphology, hybrid zone, pollen, ovule, sex allocation, Turneraceae.

\section{Introduction}

Sex allocation is the way in which a hermaphroditic flower's energy is partitioned among male and female functions (primary sex allocation) and floral display (secondary sex allocation; Goldman and Willson 1986). For plants, with their sedentary adult stages, the ecological and genetic contexts under which reproduction occurs can lead to variation in resource allocation, including flowers' morphological traits and gamete production (Ashman and Morgan 2004; Zhang 2006). In bisexual angiosperms, primary sex allocation can be quantified by assessing numbers of ovules and pollen grains produced per flower (Barrett et al. 1996), and ratios between female and male gamete production (pollen-to-ovule $[\mathrm{P}: \mathrm{O}]$ ratios) can

\footnotetext{
${ }^{1}$ Author for correspondence; e-mail: jrward@unca.edu.
}

Manuscript received October 2013; revised manuscript received January 2014; electronically published April 24, 2014. describe investment to sex-specific functions and can indicate mating systems (Cruden 1977). Intraspecific P : O ratios might remain constant because of evolutionary constraints maximizing reproductive success (Charlesworth and Charlesworth 1981) or vary with exogenous factors (Delesalle et al. 2007) such as nutrient availability, habitat characteristics, edaphic conditions, and water stress (Delph et al. 1997). Primary sex allocation can constrain total seed output (Burd 1994; Harder and Routley 2006) or affect mating patterns within and among populations (Barrett 2002a).

Floral displays and reproductive morphology, which can attract animal visitors and facilitate gamete movement, also affect the reproductive success of allogamous plants. Components of floral morphology, including petal separation and size, can influence pollinator activity and even promote prezygotic isolation (Campbell and Aldridge 2006). Within a species, flower size often varies (Cresswell 1998), and it can be genetically or ontogenetically correlated with total plant size 
(Worley and Barrett 2001; Lehtila and Holmen 2007). Spatial placement of reproductive structures within a flower can influence pollen removal, transfer, or receipt (Barrett 1990; Cresswell 2000). In heterostyly, individual plants within a population display reciprocal differences in the positioning of stigmas and anthers and typically have genetic self-incompatibilities, too (Dulberger 1992); this suite of phenotypic and genetic traits promotes outcrossing (Charlesworth and Charlesworth 1987; Lloyd and Webb 1992; Baena-Diaz et al. 2012), reduces interference during pollen receipt or removal (Bertin and Newman 1993; Barrett 2002b), and avoids inbreeding depression (Charlesworth and Charlesworth 1979). Furthermore, ratios of long and short morphs can control metapopulation dynamics or deme persistence (Brys et al. 2004; Feldman 2008). In distyly, the most common form of heterostyly, morphs are termed long (pin) or short (thrum) on the basis of style length (Barrett 2010), and floral morphs often vary in pollen production and anther/stigma lengths (Richards and Barrett 1992). Morphs display reciprocal herkogamy, in which complementary anther and stigma heights promote intermorph pollinations (Barrett 2002a). Under field conditions, perfect reciprocal herkogamy is rarely observed; instead, the physical distance between anthers and stigmas may vary among individuals and among flowers within individuals (Sanchez et al. 2008) and have consequences for compatibility (Nishihiro et al. 2000).

Members of the Piriqueta cistoides ssp. caroliniana Arbo complex (Turneraceae; hereafter referred to as P. caroliniana; Arbo 1995) were used to assess intraspecific and intermorphotype variation in primary sex allocation. This group of herbaceous, perennial hermaphrodites is found throughout the southeastern United States and the Caribbean, where it occurs in small (typically 25-100 individuals; Cruzan 2005), lowdensity (Feldman and Morris 2011) populations separated by several kilometers (Picotte et al. 2007). Plants are distylous and self-incompatible (Wang and Cruzan 1998; Tamari et al. 2001), and a single segregating locus might control both morphological separation and pollen/stigma incompatibilities (Tamari et al. 2001). More recent work has suggested that these interrelated phenotypic traits might be controlled by a supergene (see Shore et al. 2006). Piriqueta caroliniana produces actinomorphic flowers most prolifically from May to August, on multiple vegetative branches and nodes per plant (Feldman 2008), and flower morphology does not differ among nodes (J. R. Ward, personal observation). Flowers are open for $<6 \mathrm{~h} / \mathrm{d}$, regardless of pollination/fertilization status (Anton et al. 2013) or environment (field vs. greenhouse; Anton 2008), and are visited by $>40$ species of insects from at least four orders (Feldman 2008). Although symmetry does not have significant effects on $P$. caroliniana's rates of insect visitation, increased floral perimeter and area and reduced petal separation are attractive to pollinators (Anton et al. 2013).

This study focused on variation in gamete production and floral morphology for two morphotypes and their late-generation heterotic hybrids (Rhode and Cruzan 2005). The caroliniana (C) morphotype lives in well-drained quartz soils within turkey oak (Quercus laevis Walter) scrub habitats (USFWS 2013a) in southern Georgia and northern Florida, while the viridis $(\mathrm{V})$ morphotype inhabits hydric slash pine
(Pinus elliottii Engelm.) flatwood habitats (USFWS 2013b) in southern Florida (Picotte et al. 2007). Over the past $5000 \mathrm{yr}$, $\mathrm{C}$ and $\mathrm{V}$ (parental) morphotypes have interbred to produce a stable hybrid derivative ( $\mathrm{H}$ morphotype) that thrives across a broad range of water availabilities and community types throughout central Florida (Maskas and Cruzan 2000; Picotte et al. 2007), and the hybrid zone's extent and H morphotypes' frequency are expanding (Cruzan 2005). Aridity and soil nutrients vary among the morphotypes' habitats, such that $\mathrm{V}$ habitats have the highest water and nitrogen availability (Picotte et al. 2009). Hybrids exhibit heterosis and positive epistasis for vegetative traits and fruit production (Rhode and Cruzan 2005). In common field gardens, H morphotypes produce larger flowers (greater area) with less petal separation (Anton et al. 2013) than parental types.

In our survey of natural Piriqueta populations, we hypothesized that $\mathrm{H}$ morphotypes would produce more gametes and larger flowers than those from C and V populations. Previous observations of common gardens showed interannual variation in floral traits, including area and petal separation (Anton et al. 2013), so we expected to see differences over time. Since long floral morphs typically produce larger pollen grains than short morphs in distylous plants (Barrett and Cruzan 1994), including Piriqueta (M. B. Cruzan, personal observation), long morphs might experience energetic trade-offs, producing fewer total grains per flower. Long-morph flowers might devote fewer resources to male function than their short-morph conspecifics (Kohn and Barrett 1992), so we predicted that long flower morphs would produce fewer total pollen grains (but see Valois-Cuesta et al. 2012). Finally, we expected herkogamy to differ between hybrid and parental morphotypes but to be stable within and among years, as greenhouse-grown individuals showed little variation in this trait over time (Anton et al. 2013). The $P$. caroliniana study system allowed us to compare sex allocation patterns between two distinct style morphs and among hybrid and parental morphotypes and to draw conclusions about the effects of sex allocation on hybrid zone dynamics. In addition, combining measurements from fieldand greenhouse-grown plants allowed us to comment on the relative stability of observed sex allocation patterns.

\section{Material and Methods}

In July 2008 and June 2009, we sampled morphotypes (C, $\mathrm{V}, \mathrm{H}$ ) of Piriqueta caroliniana throughout their native range in Florida and southern Georgia. By measuring over multiple seasons and by resampling some populations within seasons, we could address the temporal stability of sex allocation patterns. To assess variation among populations, 1465 flowers were obtained from individual plants in 28 distinct populations $(14 \mathrm{C}, 9 \mathrm{~V}, 10 \mathrm{H})$. To determine temporal patterns in floral morphology and sex allocation, individual plants within three large $\mathrm{H}$ populations $(n>200$ individuals; mean population size in this genus $=25-100$ individuals; Cruzan 2005) were tagged, and flowers were sampled repeatedly in 2008 (231 samples over 8 d) and 2009 (334 samples over 7 d). Each plant's height, number of leaf nodes, leaf area, and fruit production were measured. Vegetative plant size was calculated as the product of total stem length and node number (Picotte et al. 2007), a parameter that predicts both future growth and 

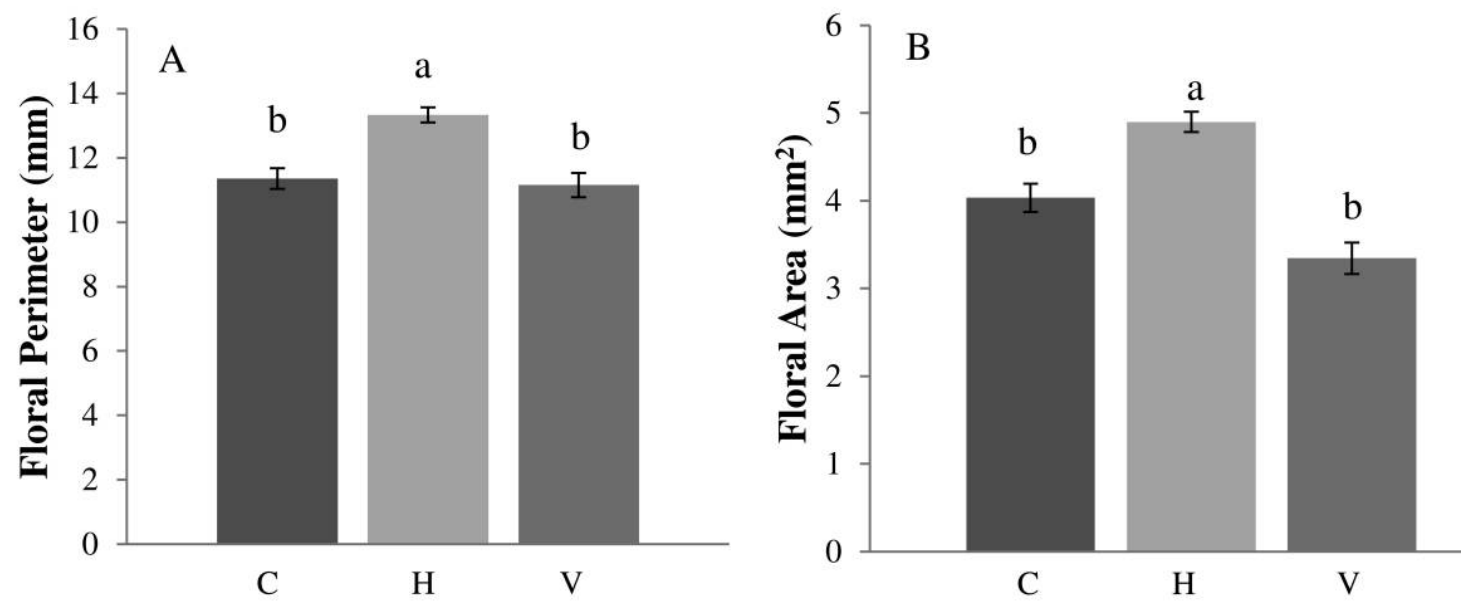

Fig. 1 Mean $( \pm \mathrm{SE})$ floral perimeter $(A)$ and area $(B)$ for field-collected caroliniana $(\mathrm{C} ; n=106)$, hybrid $(\mathrm{H} ; n=202)$, and viridis $(\mathrm{V} ; n=$ 67) morphotypes. Letters above bars indicate significant differences between means, as identified through Tukey post hoc testing.

overwinter survival (Rhode and Cruzan 2005). All flower morphs (long vs. short) were recorded, and each flower was photographed and dissected in the field. Ovaries were stored in glycerol and anthers were stored in $70 \%$ ethanol for preservation until ovule and pollen counts were conducted. Dissected flowers with intact reproductive features were collected and stored in $70 \%$ ethanol to assess spatial separation between stigmas and anthers.

Scaled photographs of field-collected flowers were measured in ImageJ (National Institutes of Health) to determine floral perimeter, floral area, and area of the smallest circle encompassing all petals. To quantify petal separation, the flower's area was subtracted from the smallest encompassing circle's area (Anton et al. 2013). Nested ANOVA (PROC MIXED, with populations nested in morphotypes; fixed term $=$ morphotype; random term = population; $\alpha=0.05$ in this and all other analysis) with Tukey's post hoc tests was run in SAS (ver. 9.2; SAS Institute 2011) to detect significant differences in floral characteristics among morphotypes. Regression (PROC REG; SAS ver. 9.2) was used to assess relationships between plant size and flower size and between plant size and fruit production. In cases where multiple flowers were sampled from single plants, mean values per plant were used in statistical analyses.

To determine gamete production, numbers of pollen and ovules were counted for each field-collected flower. Pollen and ovule counts were also recorded for each of 332 plants (one flower per plant: $31 \mathrm{C}$ from three populations; $294 \mathrm{H}$ from five populations; $7 \mathrm{~V}$ from three populations) from a longstanding greenhouse accession, allowing this study to address the effects of environmental variation on sex allocation patterns. Greenhouse plants were germinated from field-collected seeds and maintained under consistent light $(16 \mathrm{~L}: 8 \mathrm{D}$, to maximize flower production; J. R. Ward, personal observation), humidity, and watering conditions. For all samples, ovaries were cross-sectioned and mounted in $100 \%$ glycerol, dissected using a razor blade and small forceps, and examined under $40 \times$ magnification to count ovules. To evaluate pollen pro- duction, an individual's anthers were placed in $500 \mu \mathrm{L}$ of $70 \%$ ethanol and vortexed for $2 \mathrm{~min}$. Immediately following vortexing, $10 \mu \mathrm{L}$ of this solution was pipetted to cover nine squares on a hemocytometer, pollen grains in three $1-\mathrm{mm}^{2}$ squares were counted under $40 \times$ magnification, and total pollen grain counts were extrapolated from this mean (Thompson et al. 1989).

Nested ANOVA (PROC MIXED, with populations nested in morphotypes; fixed terms = morph, morphotype, year; random term = population) with Tukey's post hoc tests was run in SAS (ver. 9.2) to detect differences between style morphs, morphotypes, or years with respect to mean pollen grains per flower, mean number of ovules per flower, and mean pollento-ovule ratio. PROC REG (SAS ver. 9.2) was used to determine relationships between gamete production and plant size. In cases where multiple flowers were sampled from single plants, mean values per plant were used in statistical analyses.

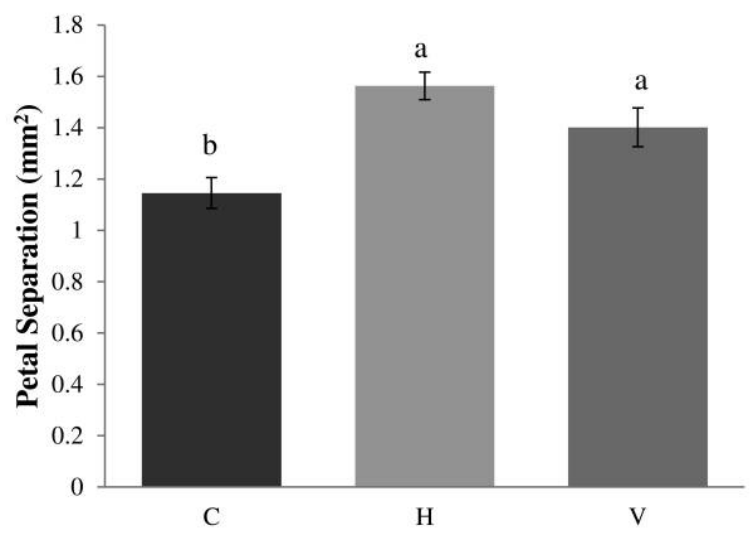

Fig. 2 Mean $( \pm \mathrm{SE})$ petal separation $\left(\mathrm{mm}^{2}\right)$ for caroliniana $(\mathrm{C}$; $n=106)$, hybrid $(\mathrm{H} ; n=202)$, and viridis ( $\mathrm{V} ; n=67$ ) morphotypes. Letters above bars indicate significant differences between means, as identified through Tukey post hoc testing. 

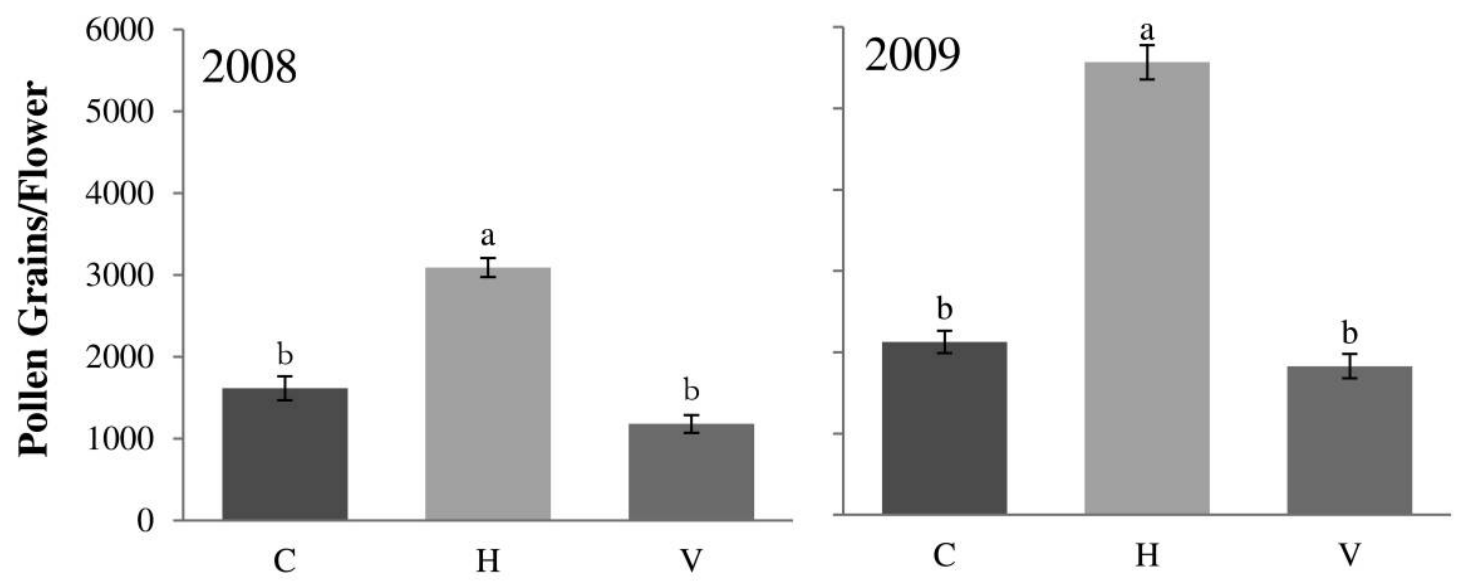

Fig. 3 Mean $( \pm \mathrm{SE})$ pollen quantity for caroliniana $(\mathrm{C} ; n=274)$, hybrid $(\mathrm{H} ; n=536)$, and viridis $(\mathrm{V} ; n=206)$ morphotypes. Letters above bars indicate significant differences between means, as identified through Tukey post hoc testing. Pollen-to-ovule ratios, driven by pollen counts, followed identical trends.

To quantify variation in stigma-anther separation, one dissected flower per plant was photographed through a compound microscope ( $40 \times$ total magnification). A subset of flowers from a greenhouse accession $(n=119$; 6 C from two populations, $44 \mathrm{H}$ from eight populations, $17 \mathrm{~V}$ from three populations) was also measured. SketchUp (ver. 7; Google) was used to add a scale to each photograph, allowing digital measurements of anthers and stigmas to be made. Length of each anther and style $(\mathrm{mm})$ and mean separation of male and female components were recorded, and the effects of morphotype and floral morph on stigma-anther separation were tested using nested ANOVA (PROC MIXED, with populations nested in morphotypes; fixed terms = morphotype, morph; random term $=$ population) with Tukey's post hoc tests in SAS (ver. 9.2). Variation in floral traits in resampled populations was assessed using repeated-measures analysis (PROC MIXED, SAS ver. 9.2).

\section{Results}

In all analyses, population had a significant effect on independent variables. Because the study's focus is on distyly and intermorphotype differences, however, the effects of population are not discussed further.

\section{Floral Architecture}

Morphotype affected all parameters examined. Hybrids had significantly larger mean perimeter $\left(F_{2,320}=27.99, P=0.001\right.$; fig. $1 A)$ and mean area $\left(F_{2,320}=27.99, P=0.001\right.$; fig. $\left.1 B\right)$
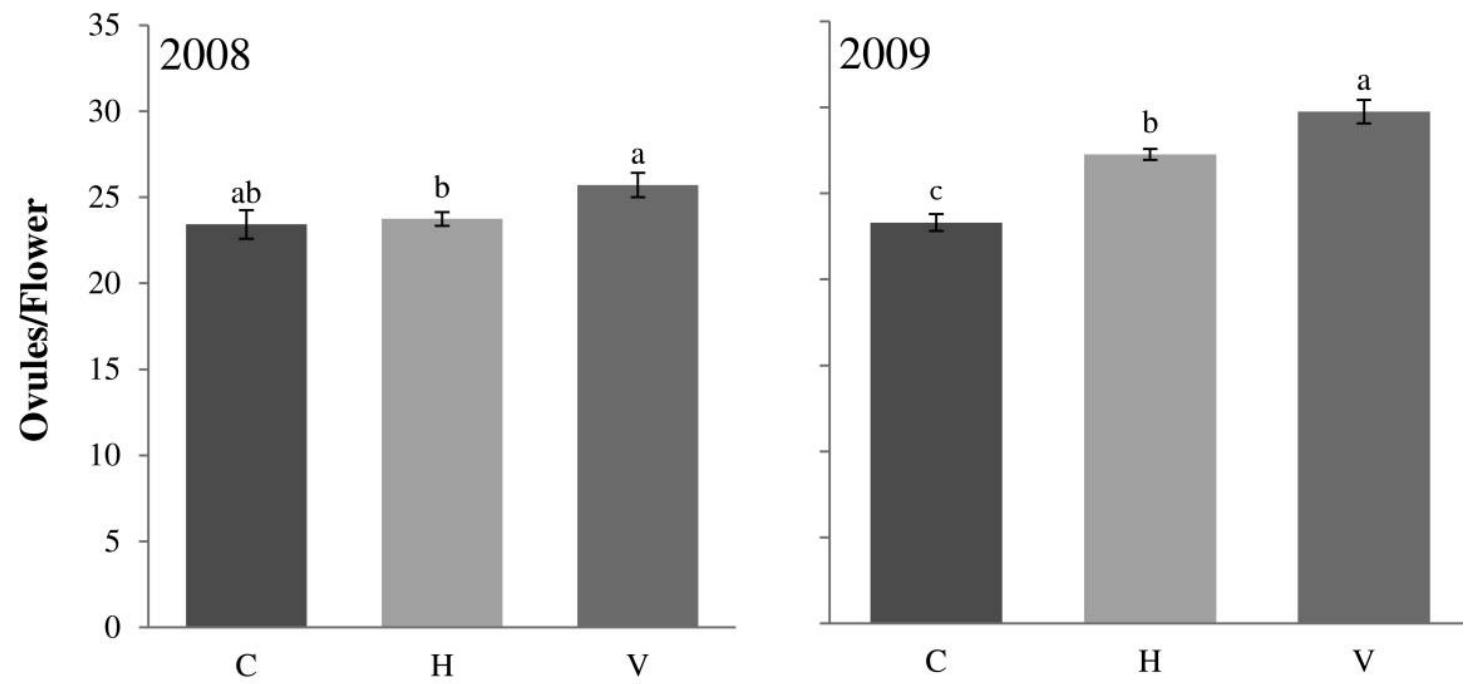

Fig. 4 Mean ( \pm SE) ovule production for caroliniana (C; $n=274)$, hybrid $(H ; n=534)$, and viridis (V; $n=206)$ morphotypes. Letters above bars indicate significant differences between means, as identified through Tukey post hoc testing. 

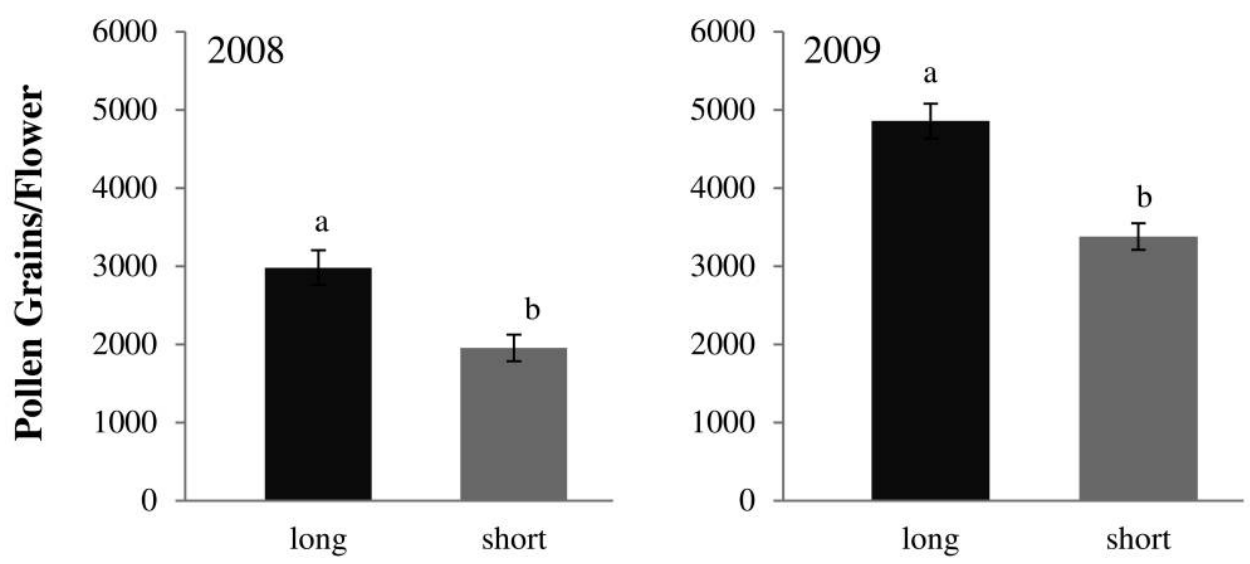

Fig. 5 Mean $( \pm$ SE) pollen quantity for long (short anther; $n=555)$ and short (long anther; $n=462)$ style morphs in two years. Ovule quantity did not vary between morphs. Letters above bars indicate significant differences between means, as identified through Tukey post hoc testing.

than either parental type. Morphotypes also differed in their petal separation $\left(F_{2,320}=9.92, P=0.001\right)$, which was lowest for $\mathrm{C}$ morphotypes (fig. 2). None of these floral traits was affected by floral morph $(P>0.05)$. Across all morphotypes, there was no relationship between plant size and individual floral area $\left(t_{375,376}=0.88, P=0.37\right)$, although larger plants produced more fruits $\left(t_{374,374}=13.53, P=0.001\right)$.

\section{Gamete Production}

As hypothesized, hybrid morphotypes from both field collections $\left(F_{2,974}=71.29, P=0.001\right.$; fig. 3$)$ and greenhouse accessions $\left(F_{2,334}=9.46, P=0.001\right)$ produced significantly more male gametes than parental lineages. In the field, pollen production differed between years and was higher in 2009 than in $2008\left(F_{1,974}=62.32, P=0.001\right)$. Repeated-measures ANOVA revealed nearly significant increases in pollen production over time, within a single season $\left(F_{1,140}=8.01, P=\right.$ $0.053)$. Ovule production per flower also differed by morphotype, with $\mathrm{V}$ plants producing the most ovules per flower under both field $\left(F_{2,972}=27.7, P=0.001\right.$; fig. 4$)$ and greenhouse $\left(F_{2,334}=8 / 95, P=0.001\right)$ conditions. More ovules were produced per flower in 2009 than in $2008\left(F_{1,972}=\right.$ 27.88, $P=0.001$ ), but repeated-measures ANOVA showed no effect of time (within a single season) on ovule production $\left(F_{1,142}=0.25, P=0.62\right)$. Pollen-to-ovule ratios differed among morphotypes in the field $\left(F_{2,964}=32.00, P=0.001\right)$ and greenhouse $\left(F_{2,334}=5.43, P=0.005\right)$ and were significantly higher for $\mathrm{H}$ morphotypes (mean \pm SE for field plants: $\mathrm{C}=72.4 \pm 6.7, \mathrm{H}=149.7 \pm 8.2, \mathrm{~V}=50.0 \pm 5.4$ ); this trend was driven by enhanced pollen production by hybrids.

Plants with short anthers (long morph) produced significantly more pollen per flower than plants with long anthers (short morph) in both years $\left(F_{1,974}=79.78, P=0.001\right.$; fig. $5)$, but ovule production per flower did not differ between floral morphs $\left(F_{1,972}=0.74, P=0.39\right)$. Pollen-to-ovule ratios, driven by pollen numbers, were higher in short-morph plants $\left(F_{1,964}=27.73, P=0.001\right)$. Larger plants produced more pollen per flower $\left(t_{1,519}=4.60, P=0.001\right)$, although this relationship was weak $\left(r^{2}=0.04\right)$. Ovule production per flower was negatively and weakly correlated with plant size $\left(t_{1,227}=-2.35, P=0.0194, r^{2}=0.02\right)$.

\section{Herkogamy}

Mean $( \pm \mathrm{SE})$ spatial separation $(\mathrm{mm})$ between anthers and stigmas was greater for short morphs than for long morphs $\left(F_{1,562}=1539.49, P=0.001\right)$, but separation did not differ among morphotypes $\left(F_{2,562}=2.31, P=0.10\right.$; fig. 6). Similar results were observed in greenhouse-grown flowers, in which separation was greater for short morphs $\left(F_{1,34}=30.64, P=\right.$ $0.001)$ but did not vary by morphotype $\left(F_{1,34}=2.30, P=\right.$ 0.12 ). In resampled populations, spatial separation did not vary within a season (effect of time: $F_{1,142}=2.30, P=0.07$ ).

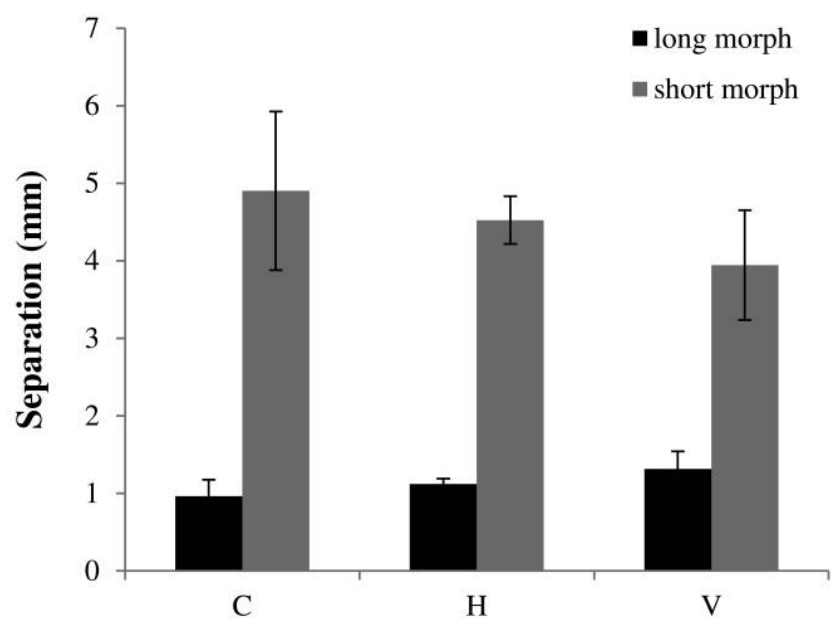

Fig. 6 Mean $( \pm \mathrm{SE})$ spatial separation $(\mathrm{mm})$ for long (short anther; $n=300$ ) and short (long anther; $n=275$ ) style morphs in two years. Spatial separation did not differ among morphotypes. 


\section{Discussion}

We found differences in flower morphology and sex allocation that were consistent with heterotic traits displayed by the $\mathrm{H}$ morphotype. Caroliniana $(\mathrm{C})$ plants had the least spatial separation between petals, but hybrid plants produced larger flowers (more perimeter and area) than either of the parental (C or V) morphotypes. Larger flowers are attractive to Piriqueta pollinators, and this trait is more important to pollinators than petal separation (Anton et al. 2013). Therefore, $\mathrm{H}$ plants in mixed populations, such as those occurring at the hybrid zone's edges (Maskas and Cruzan 2000), should receive more visitors-and perhaps then produce more seeds-than C or V morphotypes. In low-density Piriqueta populations, visitation and pollen deposition to individual flowers might be limited (Feldman 2008), triggering intraspecific competition. Thus, floral phenotypic differences and the resulting effects on pollinator behaviors could be an important factor contributing to hybrid zone expansion (Cruzan 2005) within this species complex. Petal size and separation varied among morphotypes. However, although studies of other heterostylous systems have found intermorph variation in these floral traits (Mazer and Hultgard 1993; Wolfe 2001), petal size and separation did not vary significantly between long- and short-style Piriqueta.

Larger plants produced more fruits than small plants under field conditions, as expected (Weiner et al. 2009), regardless of population of origin or morphotype. However, there was no relationship between plant size and flower size in any morphotype. The Piriqueta cistoides ssp. caroliniana complex has a generalist pollinator syndrome (Anton et al. 2013), so producing larger flowers should be advantageous. However, other studies have found trade-offs between components of sex allocation, such that large flowers produce fewer gametes per flower (Parachnowitsch and Elle 2004). Relationships between floral display size, seasonal production of gametes, and lifetime reproductive success in this long-lived perennial should be investigated further to better understand competing selection pressures on phenotypic traits related to sex allocation.

Pollen production differed among morphotypes, with hybrid plants producing more grains per flower than parental types. These patterns were expected, as hybrids are heterotic for both vegetative traits and reproductive output (Rhode and Cruzan 2005). Pollen output per flower might also influence the future composition of this species complex, allowing more late-generation hybrids to be produced at the hybrid zone's leading edge via pollen-facilitated introgression (Martin and Cruzan 1999). P : O ratios followed trends observed in pollen production. The actual values of these ratios classified Piriqueta morphotypes' reproductive system as facultative autogamy (Cruden 1977). All three morphotypes, although early-successional (ruderal) plants, are self-incompatible (Wang and Cruzan 1998), however. Lower-than-expected P : O ratios in this species complex, which could be a result of lower pollen or higher ovule production, remain unexplained.

Viridis (V) morphotypes, whose plants and flowers were typically smaller than those of other morphotypes, produced the most ovules, contrary to the predictions of size-dependent sex allocation (Brunet 1992; but see Mazer and Dawson 2001). Resource availability often limits ovule production (Lloyd and Bawa 1984), and both water and soil nutrients are more abun- dant in V habitats (Picotte et al. 2007). However, the same pattern persisted under greenhouse conditions, so the factors controlling ovule production in this group remain unknown. Although $\mathrm{H}$ morphotypes produced fewer ovules per flower than V morphotypes, previous studies (Rhode and Cruzan 2005) have shown that $\mathrm{H}$ flowers produce more seeds. This is likely due to the effects of the floral trait differences discussed above on pollinator visitation rates, but future efforts should focus on relationships among sex allocation, reproductive output, and fitness in this complex. This study revealed significant relationships between plant size and gamete production per flower, but regression statistics had little explanatory power (low $r^{2}$ ), so we expect these traits to be differentially influenced by environmental factors or other unmeasured variables. Intraand interannual variation in mean pollen and ovule production were seen under field conditions. This might be attributed to changes in exogenous factors like nutrient availability, habitat characteristics, edaphic conditions, and water stress; each of these can influence the proportion of total resources allocated to pollen and ovule production per flower (Zhang 2006).

In Piriqueta, floral morphs differed in both their pollen production and spatial separation, but they showed no differences in ovule production. Long-styled flowers, which are probably less likely to transfer pollen onto floral visitors (Beach and Bawa 1980; Cresswell 2000), produced significantly more pollen per flower than short-styled flowers. This result is not consistent with a trade-off between pollen size and number (Mazer and Hultgard 1993), although it is aligned with other studies that have shown that pin (long-morph) flowers produce more pollen, higher $\mathrm{P}$ : $\mathrm{O}$ ratios, and similar numbers of ovules than thrum (short-morph) flowers (Sampson and Krebs 2012). Reduced pollen production by short floral morphs in Piriqueta does not demonstrate enhanced male function, which has been demonstrated for short morphs in other heterostylous systems (Kohn and Barrett 1992; Valois-Cuesta et al. 2012). However, other factors that might augment male function, like faster rates of pollen germination or pollen tube growth (Melser et al. 1999; Pasonen et al. 1999), have yet to be examined in this species complex. While differences in pollen production between short- and long-styled floral morphs have been observed in other angiosperm taxa, they have not previously been reported in other Turneraceae (Swamy and Bahadur 1984).

Across all morphotypes, spatial separation was greatest for short morphs. The probability of comparable receipt and donation of male gametes via insect pollinators declines dramatically as spatial separation increases, so separation should be maximized in short morphs, which are expected to receive larger amounts of incompatible self-pollen (Barrett 1990; Ramirez and Navarro 2010). Therefore, greater stigma-anther separation in short morphs is consistent with selection for reduced pollen interference (Barrett 2002b). Resampled populations showed no significant temporal variation in degree of stigma-anther separation, suggesting that this phenotypic feature has little environmental or ontogenetic variation within the time frame of this study. However, longer-term studies of herkogamy might be informative, as reduced stigma-anther distances can be a first step toward the evolution self-compatibility (Moeller and Gerber 2005) and might not be problematic for species without pollen interference (Koelling and Karoly 2007). Future studies should better quantify the effect 
of spatial separation on pollinator effectiveness in this complex, to determine intrapopulation mating potential (Sanchez et al. 2008) or test relationships between degree of herkogamy and pollinator availability (Brys et al. 2007). We might predict that herkogamy would be stable in this complex, since pollinator activity is high across populations of different morphotypes and sizes (Anton et al. 2013).

The study of distylous systems like the $P$. cistoides caroliniana complex allows a better understanding of the role played by morphology in the evolution of self-incompatibility. Under field conditions, floral morph ratios (number of potential compatible matings) might have the most important effect on an individual's reproductive success (Brys et al. 2007), and skewed morph ratios might affect population persistence (Brys et al. 2004) and levels of genetic diversity (Meeus et al. 2012). While floral morph ratios are temporally constant in some other heterostylous species (Hodgins and Barrett 2008), functional gender expression can change over time (Gonzalez et al. 2005). In Piriqueta, ratios vary among populations and years, ranging from $7: 1$ (long to short) to $4: 13$ (J. R. Ward, personal observation); interannual variation is likely a result of metapopulation dynamics (Feldman 2008; Feldman and Morris 2011). We would predict that populations with more long morphs would produce the most seeds (Endels et al. 2002; Cawoy et al. 2006) and would be more likely to avoid extinction. In fact, a previous field study in this hybrid complex showed a lower seed set in short floral morphs, consistent with higher male function (Feldman 2008). With strong reciprocal herkogamy and self-incompatibility, though, the reproductive success of Piriqueta may be more sensitive to departures from equal floral-morph ratios.

\section{Acknowledgments}

We thank Christian Johnson, Jennafer Hamlin, and Kara Hubbard for field and greenhouse assistance and Georgia College for greenhouse space. Comments from H. David Clarke, Jonathan Horton, Robert A. Krebs, Susan Mazer, and one anonymous reviewer greatly improved the manuscript. Mila Lemaster provided logistical support; Archbold Biological Station (Eric Menges) and Tall Timbers Field Station hosted the researchers for portions of this work. Funding was provided by the University of North Carolina at Asheville's Undergraduate Research Program (to J.C. and M.L.C.) and by a Sigma Xi Grant-in-Aid of Research award (to M.L.C.).

\section{Literature Cited}

Anton KA 2008 Variation in floral morphology, pollen deposition, and pollinator effectiveness in the Piriqueta caroliniana complex. MS thesis. Portland State University, Portland, OR.

$\rightarrow$ Anton KA, JM Rhode Ward, MB Cruzan 2013 Pollinator-mediated selection on floral morphology: evidence for transgressive evolution in derived hybrid populations. J Evol Biol 26:660-673.

Arbo MM 1995 Turneraceae. Part I. Piriqueta. New York Botanical Garden, Bronx, NY.

$\rightarrow$ Ashman T, MT Morgan 2004 Explaining phenotypic selection on plant attractive characters: male function, gender balance or ecological context? Proc R Soc Biol Sci Ser B 271:553-559.

$\rightarrow$ Baena-Diaz F, J Fornoni, P Sosenski, F Molina-Freaner, S Weller, R Perez-Ishiwara, C Dominguez 2012 Changes in reciprocal herkogamy during the tristyly-distyly transition in Oxalis alpine increase efficiency in pollen transfer. J Evol Biol 28:574-583.

$\rightarrow$ Barrett SCH 1990 The evolution and adaptive significance of heterostyly. Trends Ecol Evol 5:144-148.

$\rightarrow-2002 a$ The evolution of plant sexual diversity. Nat Genet 3: $274-284$.

$\rightarrow-2002 b$ Sexual interference of the floral kind. Heredity 88:154159.

$\rightarrow-2010$ Darwin's legacy: the forms, function and sexual diversity of flowers. Philos Trans R Soc B 365:351-368.

Barrett SCH, MB Cruzan 1994 Incompatibility in heterostylous plants. Pages 189-219 in EG Williams, AE Clarke, RB Knox, eds. Genetic control of self-incompatibility and reproductive development in flowering plants. Kluwer, Netherlands.

$\rightarrow$ Barrett SCH, LD Harder, AC Worley 1996 The comparative biology of pollination and mating in flowering plants. Philos Trans R Soc B 351:1271-1280.

$\rightarrow$ Beach JH, KS Bawa 1980 Role of pollinators in the evolution of dioecy from distyly. Evolution 34:1138-1142.

$\rightarrow$ Bertin RI, CM Newman 1993 Dichogamy in angiosperms. Bot Rev 59:112-152.

$\rightarrow$ Brunet J 1992 Sex allocation in hermaphroditic plants. Trends Ecol Evol 7:79-84.

$\rightarrow$ Brys R, H Jacquemyn, L De Bruyn, M Hermy 2007 Pollination suc- cess and reproductive output in experimental populations of the selfincompatible Primula vulgaris. Int J Plant Sci 168:571-578.

$\rightarrow$ Brys R, H Jacquemyn, P Endels, F van Rossum, M Hermy, L Triest, L de Bruyn, GDE Blust 2004 Reduced reproductive success in small populations of the self-incompatible Primula vulgaris. J Ecol 92:514.

$\rightarrow$ Burd M 1994 Bateman's principle and plant reproduction: the role of pollen limitation in fruit and seed set. Bot Rev 60:83-139.

Campbell DR, G Aldridge 2006 Floral biology of hybrid zones. Pages 326-345 in LD Harder, SCH Barrett, eds. Ecology and evolution of flowers. Oxford University Press, Oxford.

$\rightarrow$ Cawoy V, V Deblauwe, B Halbrecq, J Ledent, J Kinet, A Jacquemart 2006 Morph differences and honeybee morph preference in the distylous species Fagopyrum esculentum Moench. Int J Plant Sci 167:853-861.

$\rightarrow$ Charlesworth D, B Charlesworth 1979 A model for the evolution of distyly. Am Nat 114:467-498.

$\rightarrow-1981$ Allocation of resources to male and female functions of hermaphrodites. Bot J Linn Soc 15:57-74.

$\rightarrow-1987$ Inbreeding depression and its evolutionary consequences. Annu Rev Ecol Syst 18:237-268.

$\rightarrow$ Cresswell JE 1998 Stabilizing selection and the structural variability of flowers within species. Ann Bot 81:463-473.

$\rightarrow-2000$ Manipulation of female architecture in flowers reveals a narrow optimum for pollen deposition. Ecology 81:3244-3249.

$\rightarrow$ Cruden RW 1977 Pollen-ovule ratios: a conservative indicator of breeding systems in flowering plants. Evolution 31:32-46.

$\rightarrow$ Cruzan MB 2005 Patterns of introgression across an expanding hybrid zone: analyzing historical patterns of gene flow using nonequilibrium approaches. New Phytol 167:267-278.

Delesalle V, S Mazer, H Paz 2007 Temporal variation in the pollen : ovule ratios of Clarkia (Onagraceae) taxa with contrasting mating systems: field populations. J Evol Biol 21:310-323.

$\rightarrow$ Delph LF, MH Johannsson, AG Stephenson 1997 How environmental factors affect pollen performance: ecological and evolutionary perspectives. Ecology 78:1632-1629.

Dulberger R 1992 Floral polymorphisms and their functional signif- 
icance in the heterostylous syndrome. Pages 41-84 in SCH Barrett, ed. Evolution and function of heterostyly. Springer, Berlin.

$\rightarrow$ Endels PH, H Jacquemyn, R Brys, M Hermy 2002 Changes in pinthrum ratios in populations of the heterostyle Primula vulgaris Huds. does imbalance affect population persistence? Flora 197:326-331.

$\rightarrow$ Feldman TS 2008 The plot thickens: does low density affect visitation and reproductive success in a perennial herb, and are these effects altered in the presence of a co-flowering species? Oecologia 156: 807-817.

$\rightarrow$ Feldman TS, WF Morris 2011 Higher survival at low density counteracts lower fecundity to obviate Allee effects in a perennial plant. J Ecol 99:1162-1170.

$\rightarrow$ Goldman DA, MF Willson 1986 Sex allocation in functionally hermaphroditic plants: a review and critique. Bot Rev 52:157-194.

$\rightarrow$ Gonzalez C, JF Ornelas, L Jiminez 2005 Between-year changes in functional gender expression of Palicourea padifolia (Rubiaceae), a distylous hummingbird-pollinated shrub. Ann Bot 95:371-378.

Harder LD, MB Routley 2006 Pollen and ovule fates and reproductive performance by flowering plants. Pages 61-80 in LD Harder, SCH Barrett, eds. Ecology and evolution of flowers. Oxford University Press, Oxford.

$\rightarrow$ Hodgins KA, SCH Barrett 2008 Geographic variation in floral morphology and style-morph ratios in a sexually polymorphic daffodil. Am J Bot 95:185-195.

$\rightarrow$ Koelling VA, K Karoly 2007 Self-pollen interference is absent in wild radish (Raphanus raphanistrum, Brassicaceae), a species with sporophytic self-incompatibility. Am J Bot 94:896-900.

$\rightarrow$ Kohn JR, SCH Barrett 1992 Floral manipulations reveal the cause of male fitness variation in experimental populations of Eichhornia paniculata (Pontederiaceae). Funct Ecol 6:590-595.

$\rightarrow$ Lehtila K, B Holmen 2007 Correlated effects of selection for flower size in Raphanus raphanistrum. Can J Bot 85:160-166.

Lloyd DG, KS Bawa 1984 Modification of the gender of seed plants in varying conditions. Evol Biol 17:225-388.

Lloyd DG, CJ Webb 1992 The evolution of heterostyly. Pages 151178 in SCH Barrett, ed. Evolution and function of heterostyly. Springer, Berlin.

$\rightarrow$ Martin L, MB Cruzan 1999 Patterns of hybridization in the Piriqueta caroliniana complex in central Florida: evidence for an expanding hybrid zone. Evolution 53:1037-1049.

Maskas SD, MB Cruzan 2000 Patterns of intraspecific diversification in the Piriqueta caroliniana complex in southeastern North America and the Bahamas. J Evol Biol 54:815-827.

$\rightarrow$ Mazer SJ, KA Dawson 2001 Size-dependent sex allocation within flowers of the annual herb Clarkia unguiculata (Onagraceae): ontogenetic and among-plant variation. Am J Bot 88:819-831.

$\rightarrow$ Mazer SJ, U-M Hultgard 1993 Variation and covariation among floral traits within and among four species of Northern European Primula (Primulaceae). Am J Bot 80:474-485.

$\rightarrow$ Meeus S, O Honnay, R Brys, H Jacquemyn 2012 Biased morph ratios and skewed mating success contribute to loss of genetic diversity in the distylous Pulmonaria officinalis. Ann Bot 109:227-235.

$\rightarrow$ Melser C, A Bijleveld, P Klinkhamer 1999 Late-acting inbreeding depression in both male and female function of Echium vulgare (Boraginaceae). Heredity 83:162-170.

$\rightarrow$ Moeller DA, MA Gerber 2005 Ecological context of the evolution of self-pollination in Clarkia xantiana: population size, plant communities, and reproductive assurance. Evolution 59:786-799.

$\rightarrow$ Nishihiro J, I Wahitani, JD Thomson, BA Thomson 2000 Patterns and consequences of stigma height variation in a natural population of a distylous plant, Primula sieboldii. Funct Ecol 14:502-512.

$\rightarrow$ Parachnowitsch AL, E Elle 2004 Variation in sex allocation and male- female trade-offs in six populations of Collinsia parviflora (Scrophulariaceae s.1.). Am J Bot 91:1200-1207.

$\rightarrow$ Pasonen H-L, P Pulkkinen, M Käpylä, A Blom 1999 Pollen tube growth rate and seed-siring success among Betula pendula clones. New Phytol 143:243-251.

$\rightarrow$ Picotte J, JM Rhode, MB Cruzan 2009 Leaf morphological responses to variation in water availability for plants in the Piriqueta caroliniana complex. Plant Ecol 200:267-275.

$\rightarrow$ Picotte J, D Rosenthal, J Rhode, MB Cruzan 2007 Plastic responses to temporal variation in moisture availability: consequences for water use efficiency and plant performance. Oecologia 153:821-832.

$\rightarrow$ Ramirez N, L Navarro 2010 Trends in the reproductive biology of Venezuelan Melochia (Malvaceae) species. Plant Syst Evol 289:147163.

$\rightarrow$ Rhode J, MB Cruzan 2005 Contribution of heterosis and epistasis to hybrid fitness. Am Nat 166:124-139.

Richards JH, SCH Barrett 1992 The development of heterostyly. Pages 85-227 in SCH Barrett, ed. Evolution and function of heterostyly. Springer, Berlin.

$\rightarrow$ Sampson D, R Krebs 2012 Quantitative evaluation of reciprocal herkogamy in the distylous species, Hedyotis caerulea (Rubiaceae). Plant Syst Evol 298:1361-1370.

$\rightarrow$ Sanchez JM, V Ferrero, L Navarro 2008 A new approach to the quantification of degree of reciprocity in distylous (sensu lato) plant populations. Ann Bot 102:463-472.

SAS Institute 2011 The SAS system for Windows: release 9.2. SAS Institute, Cary, NC.

$\rightarrow$ Shore JS, MM Arbo, A Fernandez 2006 Breeding system variation, genetics and evolution in the Turneraceae. New Phytol 171:539-551.

$\rightarrow$ Swamy NR, B Bahadur 1984 Pollen flow in dimorphic Turnera subulata (Turneraceae). New Phytol 98:205-209.

$\rightarrow$ Tamari F, A Athanasiou, JS Shore 2001 Pollen tube growth and inhibition in distylous and homostylous Turnera and Piriqueta (Turneraceae). Can J Bot 79:578-591.

$\rightarrow$ Thomson JDM, A McKenna, MB Cruzan 1989 Temporal patterns of nectar and pollen production in Aralia hispida: implications for reproductive success. Ecology 70:1061-1068.

US Fish and Wildlife Service 2013a Florida scrub: including scrubby flatwoods and scrubby high pine. South Florida Multi-Species Recovery Plan, Ecological Communities. US Department of the Interior, Washington, DC. http://www.fws.gov/verobeach/MSRPPDFs /FLScrub.pdf.

— $2013 b$ Hydric pine flatwoods. South Florida Multi-Species Recovery Plan, Ecological Communities. US Department of the Interior, Washington, DC. http://www.fws.gov/verobeach/MSRPPDFs /HydricPineFlat.pdf.

$\rightarrow$ Valois-Cuesta H, PJ Soriano, J Francisco Ornelas 2012 Gender specialization in Palicourea demissa (Rubiaceae), a distylous, hummingbird-pollinated treelet. Plant Syst Evol 298:975-984.

$\rightarrow$ Wang J, MB Cruzan 1998 Interspecific mating in the Piriqueta caroliniana complex: effects of pollen load size and composition. Am J Bot 82:1172-1179.

$\rightarrow$ Weiner J, LG Campbell, J Pino, L Echarte 2009 The allometry of reproduction within plant populations. J Ecol 97:1220-1233.

$\rightarrow$ Wolfe L 2001 Associations among multiple floral polymorphisms in Linum pubescens (Linaceae), a heterostylous plant. Int J Plant Sci 162:335-342.

$\rightarrow$ Worley AC, SCH Barrett 2001 Evolution of floral display in Eichhornia paniculata (Pontederiaceae): genetic correlations between flower size and number. J Evol Biol 14:469-481.

Zhang DY 2006 Evolutionarily stable reproductive investment and sex allocation in plants. Pages 41-60 in LD Harder, SCH Barrett, eds. Ecology and evolution of flowers. Oxford University Press, Oxford. 